\title{
A study of jet impingement cooling enhancement by concave and convex heat sink shape modifications
}

\author{
Marcin Froissart ${ }^{1 *}$, Paweł Ziółkowski², and Janusz Badur ${ }^{1}$ \\ ${ }^{1}$ Institute of Fluid-Flow Machinery Polish Academy of Sciences, Department of Energy Conversion, 14 Fiszera street, 80-231 \\ Gdańsk, Poland \\ ${ }^{2}$ Gdańsk University of Technology, Faculty of Mechanical Engineering and Ship Technology, 11/12 Narutowicza street, 80-233 \\ Gdańsk, Poland
}

\begin{abstract}
The rising demand for efficient cooling technologies is a strong driver of extensive research in this area. This trend is particularly strong in turbines and microprocessors technology. Presented study is focused on the jet impingement cooling concept, which is used in various configurations for many years. The potential of the heat sink shape modification is not yet fully explored. Available literature suggests that average Nusselt number can be improved by more than $10 \%$ by adding conical shape in the stagnation region. This refers to the axisymmetric case where cold-water jet impinges the surface of heated aluminium. Presented results are based on 2D axisymmetric thermal-FSI (Fluid-Solid Interaction) model, which was validated against the experiment. The objective of the presented analysis is to determine the correlation between cooling effectiveness (Nusselt number) and chosen examples of concave and convex shapes located in the jet stagnation area.
\end{abstract}

\section{Introduction}

From practice, it is well known, that jet impingement technology is one of the most effective cooling techniques, widely used in gas turbines and electronic devices. That is the reason why currently it is a subject of a worldwide extensive research projects. The main objective of them is the intensification of heat transfer between the hot solid and coolant. Available literature contains many examples of experiments $[1,2]$ which are focused on the cooling enhancement by enlarging heat exchange area. An alternative approach is based on flow instability induction, leading to the phenomena of nonstationary heat exchange [3].

Numerical simulations techniques were recently introduced $[4,5]$ to extend the understanding of numerous experiments. One of the most promising approaches is thermal-FSI, which is based on fluid and solid simulations [4]. The interaction between CFD (Computational Fluid Dynamics) and CSD (Computational Solid Dynamics) models is obtained by a coupling between solid and fluid meshes. The advantage of thermal-FSI model is a proper micro/nanoscale description of heat transfer phenomena across the boundary between fluid and solid [5,6]. Kraszewski [7] used this approach to study the transient thermal effort of Y-pipe installed in $400 \mathrm{MW}$ steam power plant.

In this paper we present a numerical simulation of particular benchmark experiment performed by Tang et al. [8], where the cold-water jet impinges into the novel single cone heat sink. Obtained results are the extension of the internal cooling research presented in works [2,9]. The flow turbulence at the bottom of the cone creates a unique transition region which is seen as a peak in the Nusselt number distribution [Fig. 5]. The optimum cone size revealed a heat transfer enhancement by $13 \%$ against the conventional flat surface [8]. The subject of this study is the heat transfer analysis of various axisymmetric shapes and comparison against Tang et al. [8] experiment. The main objective of this work is to create a reference base for further shape optimisation process. The benefit of presented results is narrowing the exploration design space to maximise heat sink cooling efficiency in the lower number of iterations. Results presented below are complementary to the Froissart et al. [10] paper focused on the heat sink cone deformation. They concluded that humped cone deformation can enhance heat transfer by three percent. That paper is based on the results presented below, because the starting point of optimisation process there was the most efficient heat sink shape - convex cone. Additionally, rounded tip was not taken into account because of its negligible effect. That property is an advantage, as tip is always deformed to some extend by the manufacturing variations.

\section{Experiment}

The subject of this paper is the investigation of jet impingement cooling enhancement by the heat sink shape modification. Crucial part of this study is the preliminary

\footnotetext{
* Corresponding author: marcin.froissart@imp.gda.pl
} 
thermal-FSI model validation against the experiment. The reason being is that every viscous model available in CFD software is only an approximation of complex physical processes. Momentum balance described by NavierStokes equations governs velocity field and pressure drop, whereas temperature distribution is determined by energy balance law.

\subsection{Jet device}

Fig. 1 below presents the jet device tested by Tang et al. [8], where the cold-water jet cools down the heat sink surface.

It contains solid blocks at the bottom and one fluid channel at the top. Aluminium base plate is heated by PTC (Positive Temperature Coefficient) heater with the heat flux density $q=80 \mathrm{~W} / \mathrm{cm}^{2}$. Adjacent copper block conducts heat towards the aluminium heat sink at the top. The boundary surface between solid and fluid is a subject of jet impingement, where heat is absorbed by the water and transported towards the outlet channels.

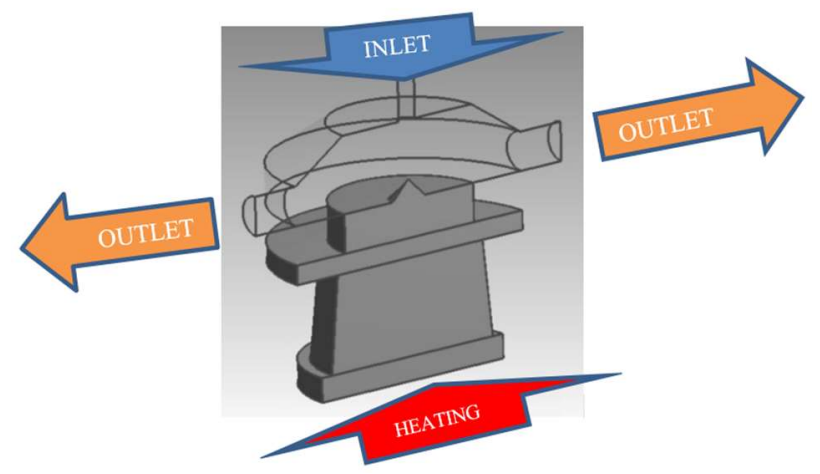

Fig. 1. Structure of the single cone heat sink jet device (symmetry plane half view)

Fig. 2 and Table 1 present key dimensions of tested heat sink and adjacent fluid channel. Water is injected through the pipe at the top and impinges into the side surface of the cone. Following that, water stream is dispersed radially and outlets through two side pipes [Fig. 1]. The heat exchange surface is bounded by the size of the heat sink radius $\left(r_{2}\right)$.

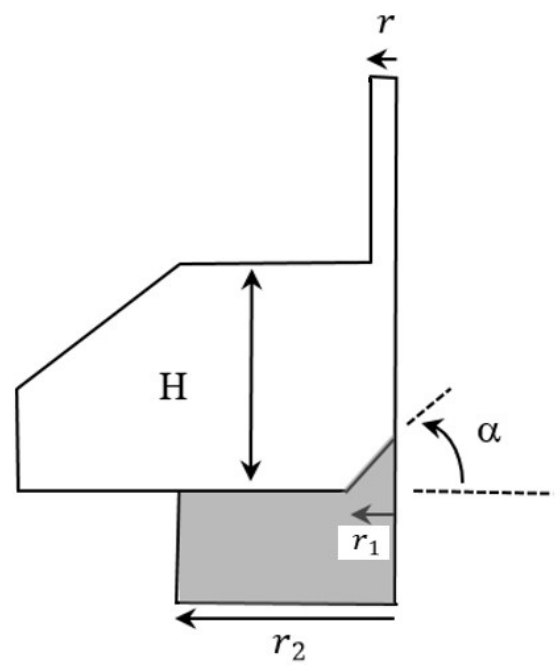

Fig. 2. Heat sink key dimensions
The second tested configuration was a flat surface ( $\alpha=0 \mathrm{deg}$ ). This case is a reference point for all analysed shapes of heat sink impingement surfaces.

Table 1. Heat sink experimental parameters

\begin{tabular}{|l|l|l|l|l|l|l|}
\hline $\begin{array}{c}r \\
{[\mathrm{~mm}]}\end{array}$ & $\begin{array}{c}r_{1} \\
{[\mathrm{~mm}]}\end{array}$ & $\begin{array}{l}\alpha \\
{[\mathrm{deg}]}\end{array}$ & $\begin{array}{c}r_{2} \\
{[\mathrm{~mm}]}\end{array}$ & $\begin{array}{l}\mathrm{H} \\
{[\mathrm{mm}]}\end{array}$ & $\begin{array}{l}\mathbf{v} \\
{[\mathrm{m} / \mathrm{s}]}\end{array}$ & $\begin{array}{l}q \\
{\left[\mathrm{~W} / \mathrm{cm}^{2}\right]}\end{array}$ \\
\hline 2 & 4 & $\begin{array}{l}45 \text { and } \\
0\end{array}$ & 16 & 16 & 6 & 80 \\
\hline
\end{tabular}

\subsection{Criteria number}

Average Nusselt number was used as a criterion for the heat exchange performance assessment. According to Tang et al. experiment [8], average Nusselt number for flat surface ( $\alpha=0 \mathrm{deg}$ ) is 1238.7 , whereas for $45 \mathrm{deg}$ convex cone this is 1343.7 .

The local Nusselt number at given radius can be calculated according to Equation 1. For analysed case, characteristic length $L=0.032 \mathrm{~m}$ and water thermal conductivity $\lambda=0.6 \mathrm{~W} / \mathrm{mK}$.

$$
N u_{r}=\frac{h_{r} L}{\lambda}=\frac{q_{r n} L}{\lambda\left(T_{r}-T_{j}\right)}
$$

where $N u_{r}$ is a Nusselt number at given radius [-], $h_{r}$ is a heat transfer coefficient at given radius $\left[\mathrm{W} /\left(\mathrm{m}^{2} \mathrm{~K}\right)\right]$, $q_{r n}$ represents normal heat flux at given radius $\left[\mathrm{W} / \mathrm{m}^{2}\right]$, $T_{r}$ is a temperature at given radius $[\mathrm{K}], T_{j}$ represents jet temperature $[\mathrm{K}]$. Area averaged Nusselt number can be calculated according to Equation 2.

$$
\overline{N u}=\frac{\bar{h} L}{\lambda}=\frac{\bar{q}_{s n} L}{\lambda\left(\bar{T}_{s}-T_{j}\right)}
$$

where $\overline{N u}$ is an area-averaged Nusselt Number [-], $\bar{h}$ represents area-averaged heat transfer coefficient $\left[\mathrm{W} /\left(\mathrm{m}^{2} \mathrm{~K}\right)\right], \bar{q}_{s n}$ is a normal area-averaged surface heat flux $\left[\mathrm{W} /\left(\mathrm{m}^{2}\right)\right], \quad \bar{T}_{s}$ represents area-averaged surface temperature $[\mathrm{K}]$.

\section{Analysis}

Experimental model presented in Fig. 1 is very close to the axisymmetric case, so it was converted into the 2D axisymmetric thermal-FSI model. This was done in contrast to the Tang et al. approach [8], where a 3D sector was modelled and analysed. The comparison between both models revealed, that Nusselt number distribution is similar, so 2D model was accepted for further analysis.

\subsection{Governing equations}

2D axisymmetric thermal-FSI model couples boundary conditions between solid and fluid domains. On the solid side, for the preliminary thermal-FSI approach, CSD analysis uses heat conduction equations, which is a standard approach in commercial Finite Element Analysis software. On the fluid side problem is much more complex, which is well reflected by the set of equations: 


$$
\frac{\partial}{\partial t}\left\{\begin{array}{c}
\rho \\
\rho \mathbf{v} \\
\rho e \\
\rho k \\
\rho \varepsilon
\end{array}\right\}+\operatorname{div}\left\{\begin{array}{c}
\rho \mathbf{v} \\
(\rho \mathbf{v} \otimes \mathbf{v})+p \mathbf{I} \\
(\rho e+p) \mathbf{v} \\
\rho \mathbf{v} k \\
\rho \mathbf{v} \varepsilon
\end{array}\right\}=\operatorname{div}\left\{\begin{array}{c}
0 \\
\mathbf{t}^{\mathbf{c}} \\
\mathbf{t}^{\mathrm{v}} \mathbf{v}+\mathbf{q}^{\mathrm{c}} \\
\mathbf{J}_{k} \\
\mathbf{J}_{\varepsilon}
\end{array}\right\}+\left\{\begin{array}{c}
0 \\
\rho \mathbf{b} \\
\rho S_{e} \\
\rho S_{k} \\
\rho S_{\varepsilon}
\end{array}\right\}
$$

where $\rho$ is a density $\left[\mathrm{kg} / \mathrm{m}^{3}\right], \mathbf{v}$ represents velocity $[\mathrm{m} / \mathrm{s}]$, $p$ is a pressure [Pa], $\mathbf{I}$ is a unit tensor [-], $\mathbf{t}^{\mathrm{t}}$ is a total viscous stress tensor $[\mathrm{Pa}], \mathbf{b}$ is a gravitation force $[\mathrm{N}], e$ represents the sum of specific internal and specific kinetic energy $[\mathrm{J} / \mathrm{kg}], \mathbf{q}^{t}$ is a total heat flux $\left[\mathrm{W} / \mathrm{m}^{2}\right], \mathbf{J}_{k}$ is a diffusion flux of turbulent kinetic energy $\mathrm{k}\left[1 / \mathrm{s}^{3}\right], \mathbf{J}_{\varepsilon}$ is a diffusion flux of kinetic energy dissipation $\varepsilon\left[1 / \mathrm{s}^{4}\right], S_{k}$ represents source of turbulent kinetic energy $\left[\mathrm{m}^{2} / \mathrm{s}^{3}\right], S_{\varepsilon}$ is a source of turbulent kinetic energy dissipation $\left[\mathrm{m}^{2} / \mathrm{s}^{4}\right]$.

According to Tang et al. study [8], analysed problem can be well modelled using $k-\varepsilon$ RNG (renormalization group) viscus model, which is one of the most common Reynolds-Averaged Navier-Stokes (RANS) models. However, to apply full thermal-FSI approach it is necessary to obtain fields of stress, strain and deformation, similar like in article [11].

\subsection{Model summary}

Heat sink and the cooling fluid domains have been discretized by a quadrilateral dominant mesh, steeply refined in the normal surface direction. Performed sensitivity study proved that further mesh refinement does not influence the computational results significantly. Furthermore, consistent mesh definition was used for all geometries, so similar numerical error is expected for all cases. It has been assumed that the surface structure of the pipes can be treated as a smooth and homogeneous one. Wall function $Y^{+}$lower than one has been implemented for most impingement surface area. The standard SIMPLE (Semi-Implicit Method for Pressure-Linked Equations) method has been employed for pressurevelocity coupling. The second order upwind schemes have been chosen for the solution of the convection term in governing equations. The diffusion terms have been central-differenced with the second order accuracy as well. The detailed methodology of numerical integration regarding the set of governing equations can be found in work [12].

\section{Results}

\subsection{Field of velocity}

Velocity plots shown below visualise the differences in the flow structure for each analysed geometry. Fig. 3 compares flat geometry against the 45 deg convex cone. First important difference is the size of the stagnation zone situated directly below the inlet, where recirculated water reduces impingement effect. The other key difference is the presence of the heat transfer transition zone at the bottom of the cone. High velocity patch along impinged surface marks the region where streamlines have some velocity towards the metal. That creates shear force which reduces the thickness of insulating boundary layer, leading to the heat exchange improvement. This is well reflected on Fig. 5, where convex cone generates Nusselt number peak at the bottom of the cone. Fig. 4 shows all analysed cases.

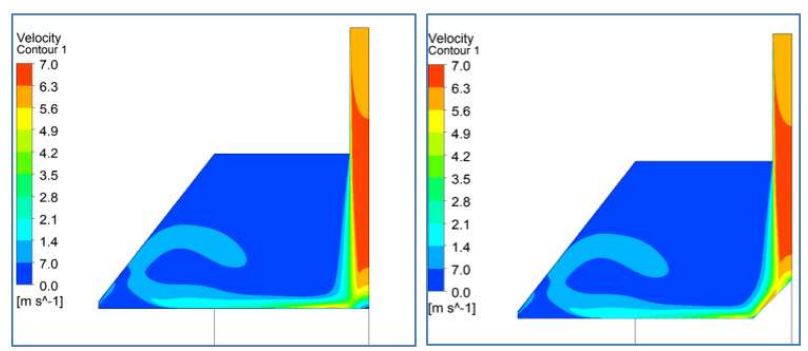

Fig. 3. Reference heat sink velocity - flat (left) and $45 \mathrm{deg}$ convex cone (right)

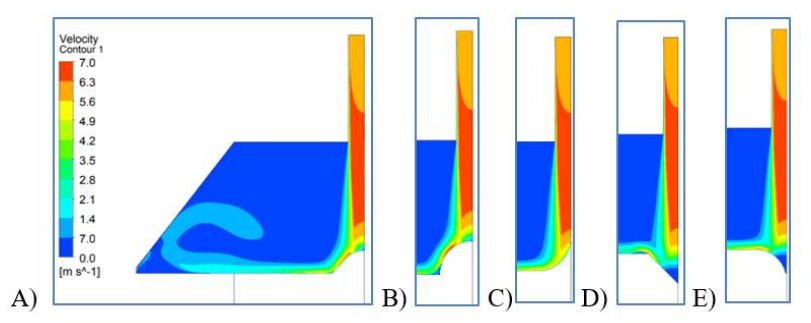

Fig. 4. Heat sink modifications - A) 45 deg convex cone with rounded top, B) convex semicircle, C) convex arc, D) concave 45 deg cone and E) concave arc

\subsection{Cooling efficiency}

Table 2 summarises cooling efficiency for all analysed heat sink shapes. It shows that all convex shapes enhance cooling effectiveness, which is opposite to concave cases where cooling effectiveness decreases. The reference geometry is the flat surface with Nusselt number equal to 1291.

Table 2. Average Nusselt numbers for analysed shapes

\begin{tabular}{|l|l|r|}
\hline \multicolumn{1}{|c|}{ Shape } & Average Nu [-] \\
\hline \hline \multirow{5}{*}{ Convex } & Flat & 1290.9 \\
\cline { 2 - 3 } & $\begin{array}{l}45 \text { deg cone } \\
\text { cone }\end{array}$ & 1347.2 \\
\cline { 2 - 3 } & Semicircle & 1347.6 \\
\cline { 2 - 3 } & Arc & 1329.8 \\
\hline \multirow{2}{*}{ Concave } & 45 deg cone & 1310.7 \\
\cline { 2 - 3 } & Arc & 1072.2 \\
\hline
\end{tabular}

Fig. 5 presents radial Nusselt number comparison between flat and convex cones. Difference between 0 and $2 \mathrm{~mm}$ is driven by the fact, that cones tip breaks stagnation region reducing the thickness of insulating boundary layer. This effect is reduced by adding rounded tip to the cone (Fig. 3 vs. Fig. 4A comparison). Negative peak at 4 $\mathrm{mm}$ is the consequence of a recirculation region, which forms additional resistance to the heat exchange process. Positive peak at $4.5 \mathrm{~mm}$ (transition region) is driven by 
the fact, that water impinges flat surface leading to the reduction of boundary layer. That region is unaffected by the shape of the cone tip. Convex semicircle is worse than cone, because it introduces larger recirculation zone. Convex arc is very similar to the flat surface with very modest transition zone.

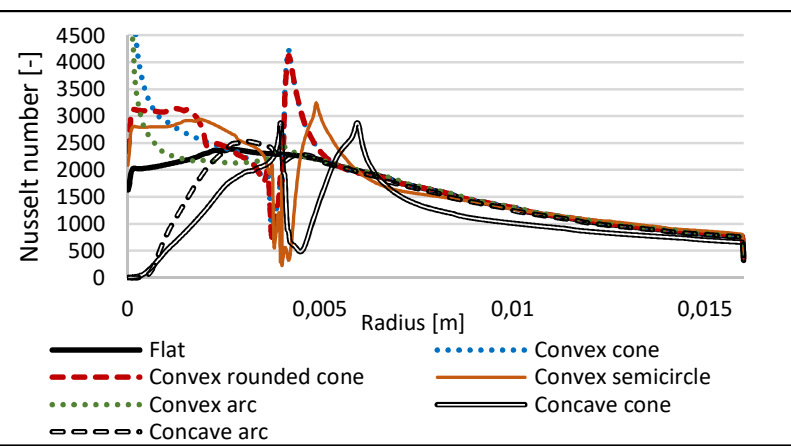

Fig. 4. Radial Nusselt number distribution for analysed heat sink shapes

Fig. 5 presents also concave geometries - cone and arc. Both are worse than the flat surface due to the significant recirculation zone in the middle, which has got detrimental impact on average cooling performance. Concave cone creates inverted recirculation zone around the radius of $5 \mathrm{~mm}$, which drops Nusselt number even more along the flow.

\section{Conclusions}

Nusselt number comparison is a universal method to assess heat transfer efficiency, so it was used to rank analysed shapes of heat sink. According to Table 2, the most efficient shape is convex cone with rounded tip. However, the main objective of this study is to check the correlation between the particular shape and cooling efficiency distribution.

In depth analysis of obtained results should help to find more efficient heat sink shape than convex cone. Special attention should be paid to improve the transition region at the cone bottom, where recirculation zone reduces heat transfer coefficient.

Further research is recommended to confirm jet impingement cooling enhancement for a gas coolant.

The research leading to these results has received funding from the Norway Grants 2014-2021 via the National Centre for Research and Development. Article has been prepared within the frame of the project: "Negative $\mathrm{CO} 2$ emission gas power plant" - NOR/POLNORCCS/ NEGATIVE-CO2-PP/0009/201900 which is co-financed by programme "Applied research" under the Norwegian Financial Mechanisms 2014-2021 POLNOR 2019 - Development of CO2 capture solutions integrated in power and industry processes.

\section{References}

1. G. Naterer, Advanced Heat Transfer $2^{\text {nd }}$ Edition, CRC Press Taylor \& Francis Gr. Boca Raton (2018)

2. P. Smakulski, S. Pietrowicz, Appl. Thermal Eng. 104, 636-645 (2016)

3. P. Glouannec, B. Michel, G. Delamarre, Y. Grohens, Appl. Thermal Eng. 73, 196-204 (2014)

4. J. Badur, P. Ziółkowski, S. Kornet, T. Kowalczyk, K. Banaś, M. Bryk, P.J. Ziółkowski, M. Stajnke, J. of Theoretical and Appl. Mechanics 56-1, 329-332 (2018)

5. P. Ziółkowski, J. Badur, Int. J. of Numerical Methods for Heat \& Fluid flow 28-1, 64-80 (2018)

6. T. Ochrymiuk, J. of Thermal Science 26-5,459-464 (2017)

7. B. Kraszewski, Case Studies in Thermal Engineering 21, 100728 (2020)

8. Z. Tang, Q. Liu, H. Li, X. Min, Appl. Thermal Eng. 127, 906-914 (2017)

9. S. Gumkowski, Hydrodynamika $i$ wymiana ciepta warstw cieczy powstatych na powierzchni ciata statego $z$ uderzajacych strug, Wydawnictwo Politechniki Gdańskiej Seria Monografie 84, (2007)

10. M. Froissart, P. Ziółkowski, W. Dudda, J. Badur, Case Studies in Thermal Engineering 28, 101445 (2021)

11. J. Badur, P. Ziółkowski, D. Sławiński, S. Kornet, Energy 92,142-152 (2015)

12. J. Badur, Numerical modelling of sustainable combustion in gas turbines, IFFM Publishers Gdańsk, (2003) 